\title{
O método Análise de Cobertura Jornalística e o acontecimento noticioso da doença do ex-presidente Lula1
}

Gislene Silva²

Rosana de Lima Soares ${ }^{3}$

1 Texto originalmente apresentado durante $\mathrm{o} 10^{\circ}$ Encontro Nacional de Pesquisadores em Jornalismo (SBPJor), realizado em novembro de 2012, em Curitiba.

2 Professora do Programa de Pós-Graduação em Jornalismo da Universidade Federal de Santa Catarina (UFSC). Doutora em Ciências Sociais/Antropologia pela Pontifícia Universidade de São Paulo (PUC-SP), com pós-doutorado na Universidade de São Paulo (USP). gislenedasilva@gmail.com.

3 Professora do Programa de Pós-Graduação em Meios e Processos Audiovisuais e do Departamento de Jornalismo e Editoração da Escola de Comunicações e Artes da Universidade de São Paulo (USP). Doutora em Ciências da Comunicação pela mesma universidade. rosanasoares@gmail.com. 


\section{Resumo}

Nesta reflexão sobre o jornalismo defendemos uma perspectiva teórico-epistemológica, pela qual entendemos ser metodologicamente viável pesquisar em uma das três instâncias do circuito comunicativo (produção, produto e recepção) dinâmicas que informem sobre as demais. Tomamos o pressuposto de que o acontecimento jornalístico pode ser observado e analisado por meio das marcas que o processo de produção da notícia deixa visíveis no próprio produto acabado. Assim, a nossa hipótese sugere que as coberturas jornalísticas, entendidas como estratégias de apuração e angulação, configuram um mesmo acontecimento social em diferentes acontecimentos jornalísticos. Como objetivo último, a reflexão trazida aqui quer investir na notícia como tradução do fato, mais conceitualmente como tradução cultural.

\section{Palavras-chave}

Jornalismo, notícia, cobertura, tradução, discurso, narrativa.

\section{Abstract}

In the present reflection on journalism we argue for an specific theoretical and epistemological perspective by which we understand to be methodologically possible to perform a research in any of the three instances of the communicational circuit (production, product and reception), observing the dynamics of each of them informing the other. We assume as a presupposition that the journalistic endeavor can be observed and analyzed trough the visible marks that the production process imposes to the final product. Thus, our research hipotesys suggests that journalistic news coverage, as being a strategy for news investigation and focus, can configure the same event into different journalistic endeavors. As our ultimate goal, the research should cope with journalistic news as fact translation, more conceptually speaking, as cultural translation.

\section{Keywords}

Journalism, news, news coverage, translation, discourse, narrative. 
Nesta reflexão sobre o jornalismo defendemos uma perspectiva teórico-epistemológica, partimos de um pressuposto e nos orientamos por uma hipótese. A perspectiva teórico-epistemológica, que foge ao modelo fragmentário do processo jornalístico, no qual produção, produto (mensagem/ discurso) e recepção são tomados como categorias estanques, entende ser metodologicamente viável pesquisar em uma destas três instâncias do circuito comunicativo dinâmicas que informem sobre as demais. Isso significa que, além de perceber o processo produtivo da notícia no produto (texto), poderíamos também investigar o receptor nas práticas da produção ou nos informar sobre a produção observando as práticas de recepção (SILVA \& MAIA, 2011a).

Com isso pontuamos que, em se tratando de textos jornalísticos, o processo de produção não desaparece no produto. Pelo contrário, o processo manifesta-se no produto, nele deixando suas marcas em maior ou menor medida. Tomamos, portanto, o pressuposto de que o acontecimento jornalístico pode ser observado e analisado por meio das marcas que o processo de produção da notícia deixa visíveis no próprio produto acabado. Assim, nossa hipótese sugere que as coberturas jornalísticas, entendidas como estratégias de apuração e angulação, configuram um mesmo acontecimento social em diferentes acontecimentos jornalísticos. Como objetivo último, a reflexão trazida aqui quer investir na notícia como tradução do fato, mais conceitualmente como tradução cultural.

Para problematizar a notícia como tradução cultural, retomamos nossa proposição ${ }^{4}$ de articulação teórica entre dois campos aparentemente desconexos - os estudos de jornalismo e de tradução -, que têm como um de seus objetivos demonstrar possibilidades que ultrapassem a visão hegemônica de que o jornalismo traduz objetivamente fatos cotidianos para aqueles que não os vivenciaram e que a tradução linguística traduz textos originais para os que não podem decodificá-los, ambos os processos feitos de modo fiel, objetivo e veraz.

4 Proposição feita pela primeira vez no artigo "O jornalismo como tradução: fabulação narrativa e imaginário social", apresentado por Rosana de Lima Soares e Gislene Silva no Grupo de Trabalho Cultura das Mídias do XXI Encontro da Compós, na Universidade Federal de Juiz de Fora, Juiz de Fora, de 12 a 15 de junho de 2012. 
Tais visões compartilham a crença em certas dicotomias, como a separação entre referencialidade e ficcionalidade, ou entre fato e relato. A essa tradição da objetividade jornalística e da fidelidade ao texto contrapomos a assunção do caráter narrativo e de fabulação desses discursos, os indícios culturais neles presentes e as diferentes configurações de um mesmo acontecimento social quando este é apresentado como acontecimento jornalístico, como notícia. O acontecimento social a ser analisado trata da doença do ex-presidente Lula e foi divulgado como notícia imediata no sábado, 30 de outubro de 2011 . No sábado seguinte, temos em mãos os acontecimentos jornalísticos sobre esse acontecimento: são quatro matérias de capa das quatro principais revistas semanais brasileiras, Época, Veja, IstoÉ e Carta Capital. Esses exemplares compõem o objeto empírico desta nossa reflexão.

\section{O método Análise de Cobertura Jornalística}

Concebemos o método de Análise de Cobertura Jornalística (ACJ) (SILVA \& MAIA, 2011a) para examinar como um determinado veículo estrutura a cobertura de assuntos em geral ou de acontecimentos factuais específicos, explorando as marcas das técnicas e estratégias de apuração, composição, disposição e, consequentemente, angulação da notícia nas páginas do veículo ${ }^{5}$. Com isso discutimos o próprio conceito de cobertura jornalística. O método se organiza em um protocolo que tenta verificar como o texto publicado revela aspectos do processo produtivo da notícia, procurando (a) não deixar que tais aspectos fiquem subsumidos na opção pela Análise de Conteúdo, (b) não adotar um conceito reducionista de newsmaking e (c) não esquecer as opções e decisões de cobertura para a compreensão do discurso jornalístico delas resultante.

O método de Análise de Cobertura Jornalística pode ser empregado em matérias jornalísticas sobre qualquer tema/assunto/acontecimento. Também é indicado para comparar tais marcas em diferentes veículos, seja sobre um 
caso particular no momento presente ou sobre temáticas que se repetem. Além disso, comporta o estudo de processos produtivos do passado, bem como de transformações na cobertura ao longo do tempo, sobretudo quando o corpus envolve um recorte temporal extenso. Quando há ênfase no contexto sóciohistórico-cultural, possibilita relacionar a produção à influência de forças conjunturais, como na pesquisa sobre textos jornalísticos produzidos durante a ditadura militar, períodos eleitorais, grandes eventos, desastres naturais, guerras, entre outros. O protocolo metodológico, ao final, ajuda também a identificar e tipificar especificidades da atividade jornalística, mapeando tendências e possíveis lacunas na obtenção, averiguação e apresentação das informações. Com a aplicação da $\mathrm{ACJ}$ estamos interessadas em investigar a conformação do acontecimento jornalístico que se dá já nas estratégias e técnicas de apuração, composição e disposição visíveis no texto - no caso, o impresso.

Destacamos aqui a consciência de que nem todos os aspectos implicados no processo produtivo podem ser acessados através do produto.

Após ser recortado como produção, o objeto jornalismo continua a desdobrar-se em diferentes esferas de análise. As formas como as organizações jornalísticas administram e planejam internamente as atividades produtivas talvez sejam mais adequadamente captadas por meio do acompanhamento das rotinas de trabalho, junto aos profissionais da redação (SILVA \& MAIA, 2011b, p.40).

O protocolo de Análise de Cobertura Jornalística, voltado neste momento para textos jornalísticos impressos e informativos ${ }^{6}$, organiza-se em três níveis analíticos $-\left(1^{\circ}\right)$ marcas da apuração, $\left(2^{\circ}\right)$ marcas da composição do produto e (30) aspectos da caracterização contextual.

6 Ponte (2005) propõe um Protocolo de Análise de Conteúdo detalhado para investigar a construção da infância pelo discurso jornalístico. Embora se apoie apenas em variáveis temáticas e formais e concentre-se no estudo da mensagem, o roteiro elaborado pela autora ajuda a pensar o protocolo de Análise de Cobertura Jornalística. 
Cada um deles olha para o objeto de estudo a partir de uma lente diferente. O primeiro, mais específico, funciona como uma teleobjetiva: recai exclusivamente sobre a matéria jornalística - tomada de forma isolada -, explorando indícios do método de apuração e da estratégia de cobertura em close-up. O segundo corresponde a uma lente normal, de alcance médio, pois que oferece uma visão um pouco mais aberta do objeto, agora enfocando não só o texto, mas o conjunto amplo do produto, como localização na página, diagramação, foto etc. E o terceiro atua como uma grande angular - não capta detalhes, mas oferece um plano geral do objeto, captando aspectos da dimensão organizacional e do contexto sócio-histórico-cultural em que se insere a produção jornalística. Os dois primeiros níveis constituem a espinha dorsal do protocolo, considerando a análise do processo produtivo a partir do produto; o último nível é complementar, visto que tem por objetivo contextualizar os dados obtidos nos níveis 1 e 2, além de requerer a combinação com outros métodos para aprofundamento da pesquisa (SILVA; MAIA, 2011b, p.42).

De modo resumido7, no 10 nível/Marcas da apuração observa-se (1) Assinatura: local (repórter da matriz da redação); correspondente; enviado especial; colaborador; agência de notícias; não assinado. (2) Local de apuração/ acesso do jornalista ao local do acontecimento: se apuração in loco ou não; (3) Origem da informação: trata das fontes consultadas, de sua natureza (humana, documental ou eletrônica) e sua posição, observando-se (a) Informações de primeira mão: com fontes do poder público, fontes institucionais, fontes cidadãs, fontes especializadas/comentadores, assessoria de imprensa, fontes nãoconvencionais e recursos alternativos (disfarce, infiltração etc.). (b) Informações de segunda mão: com agências de notícias, outros veículos jornalísticos, publicações científicas, documentos impressos e eletrônicos, informações obtidas na internet, material de reedição e de republicação, publicação de conteúdo de outros veículos. No 20 nível/Marcas da composição do produto são observados (1) Gênero jornalístico/Natureza do texto informativo: nota; notícia/matéria; fotonotícia/fotolegenda; entrevista; reportagem; reportagem especial/dossiê. (2) Localização do texto no veículo/Destaque: página par ou ímpar; quadrante superior direito/esquerdo, inferior direito/esquerdo; metade 
superior ou inferior; página inteira; várias páginas (quantas); editoria/caderno ou seção; manchete, chamada de capa ou apenas texto. (3) Recursos gráficosvisuais (próprios de agência de notícias, de assessoria de imprensa ou de outra fonte, conforme a classificação do item três): fotografia; gráfico ou tabela; boxe; infográfico; imagem não-fotográfica (como ilustrações e montagens). E, por fim, no 30 nível/Aspectos do contexto da publicação analisa-se: (1) Contexto interno: caracterização visual, editorial e organizacional do veículo/empresa. Pode incluir aspectos como perfil da redação, rotinas produtivas, orientações editoriais expressas, tiragem, área de abrangência, estrutura de produção própria, público-alvo, formato do produto, se produto segmentado/dirigido. (2) Contexto externo: caracterização do tema/fato/assunto específico da cobertura e da conjuntura sócio-histórico-cultural envolvente.

No conjunto, investigam-se as decisões editoriais que deixam suas marcas no produto noticioso e, percorrendo tais marcas, busca-se compreender a configuração do acontecimento publicado. No caso específico da cobertura jornalística aqui investigada, sobre a doença do ex-presidente Lula divulgada nas capas de quatro revistas semanais de informação no mesmo fim de semana, a ACJ será aplicada com ênfase nas marcas da apuração e da composição.

\section{Pensar a notícia como tradução}

Em trabalho recente ${ }^{8}$, fizemos uma primeira aproximação para articular dois campos aparentemente desconexos - os estudos de jornalismo e os estudos de tradução. O propósito primeiro foi discutir possibilidades que ultrapassem duas visões tradicionais: a de que o jornalismo traduz fatos cotidianos para aqueles que não os vivenciaram em tempo real - tradução esta realizada de modo fiel, objetivo e veraz - e a de que a tradução linguística traduz textos originais para aqueles incapazes de decodificá-los em suas línguas estrangeiras 
- e, portanto, também de modo fiel, objetivo e veraz. Tais visões compartilham a crença em certas dicotomias persistentes ao longo da história do pensamento ocidental, como a separação entre verdade e linguagem, referencialidade e ficcionalidade, realidade e fantasia, fato e relato. No caso da tradução, os conteúdos traduzidos poderiam ser reproduzidos de modo simétrico; no caso do jornalismo, os acontecimentos traduzidos estariam em outro lugar que não o discurso, lá onde se supõe a realidade.

\begin{abstract}
Em ambos podemos identificar a noção de um "texto-fonte" (fatos brutos ou textos originais) em relação ao qual haveria um compromisso com a acuidade do processo tradutório e a verossimilhança em seu resultado final, representado pelo texto traduzido. No jornalismo, mais do que no da tradução - cuja materialidade discursiva já obriga a uma percepção de que, mesmo no caso da tradução linguística, não há um grau-zero de onde partem as interpretações - notamos um saudosismo pela origem (o fato antes do relato, o acontecimento antes da linguagem), como se ao jornalismo fosse possível aprisionar o presente ou apreender o real (SOARES; SILVA, 2012).
\end{abstract}

Retomamos o paradoxo de que "o jornalismo, ao mesmo tempo em que se pretende objetivo e imparcial, realiza todo o tempo um trabalho de tradução dos fatos em relato" e concluímos que " ao contrário do acesso à verdade e à representação fiel da realidade, é um processo de descontinuidades que se inscreve no fazer jornalístico, encontrando, assim, ecos com o campo de estudos da tradução" (SOARES; SILVA, 2012). Na perspectiva que trabalhamos, as dicotomias iniciais se desfazem, diluindo a oposição entre verdade e linguagem, realidade e fantasia, pois o que temos são fabulações narrativas tecendo imaginários sociais, especialmente se tomarmos os discursos midiáticos como lugar privilegiado para tal articulação. Voltamos a perguntar, porém, por que o campo do jornalismo tangencia essas questões sem jamais parecer ultrapassá-las? Talvez porque um de seus principais fundamentos seja, justamente, considerar-se como lugar de organização da realidade. Assim, quando trabalhamos com a ideia de o fazer jornalístico ser uma instância que 
traduz a realidade para aqueles que não podem vê-la (estar lá em sentido literal ou figurado), queremos apontar que tal como a tradução, a produção da notícia é prática linguageira e, por isso mesmo, produção incansável de discursos sobre discursos (SOARES, 2010). Logo, o texto jornalístico, assim como o texto traduzido, não é verdadeiro ou falso; ele é um texto outro, em constante relação de aproximação e afastamento com os acontecimentos sociais dos quais trata, sobre os quais faz a cobertura jornalística. E uma vez que o texto jornalístico é uma forma de tradução dos fatos, ele está inserido no campo da "tradução cultural" e dos modos de construção simbólica da sociedade.

Há pesquisas brasileiras que se dedicam a estudar a prática da tradução nas redações e a difusão de notícias recebidas de agências internacionais. Segundo M. Zipser, pioneira nas investigações sobre as interfaces traduçãojornalismo no Brasil ${ }^{9}$,

uma tradução "fiel" ao texto-fonte e, por conseguinte, à cultura de partida não atenderia necessariamente às exigências do veículo e do público a que se destinam. A tradução no ambiente jornalístico, portanto, não poderia atender unicamente aos critérios de fidelidade à letra do textofonte, mas teria de levar em conta, igualmente, uma série de fatores que caracterizam o texto jornalístico como tal (ZIPSER, 2002, p.6).

Assim, a notícia apresentada ao público em diferentes culturas pode ser considerada tradução desse fato noticioso, no sentido de representação cultural. $\mathrm{O}$ argumento de $\mathrm{M}$. Zipser se firma no paralelismo que faz entre o entendimento comum da tradução como mera transcodificação e a percepção do texto jornalístico como expressão objetiva da realidade: "Assim como para a tradução já não se pode mais pensar numa acepção de transcodificação desvinculada da questão cultural, também para o jornalismo não se pode pensar na tradução de

9 Diversas dissertações e teses têm sido desenvolvidas nessa direção no grupo de pesquisa Trac - Tradução e Cultura, coordenado pela profa. dra. Meta Zipser, do Programa de Pós-Graduação em Estudos da Tradução da Universidade Federal de Santa Catarina (UFSC), abordagem que, a nosso ver, merece ser investigada também no âmbito das mídias e, mais especificamente, do jornalismo. 
fatos sem a devida referência à cultura local" (ZIPSER, 2002, p.12). M. Zipser trabalha com o conceito de tradução como "representação cultural" e orienta pesquisas que buscam marcas culturais em textos jornalísticos, comparando publicações da imprensa brasileira e de outros países no tratamento de um mesmo acontecimento noticioso ${ }^{10}$. Interessa-nos pensar a partir de M. Zipser o passo seguinte, não só as dissonâncias nas transposições das notícias de uma cultura de um país para outro, mas as diferenças na abordagem jornalística sobre um mesmo fato dentro de uma mesma cultura.

Tais proposições nos valem na medida em que enfrentam uma visão hegemônica no campo dos estudos e nas práticas de jornalismo, qual seja, o entendimento rotineiro de que o acontecimento é o fato que acontece na realidade e de que ao jornalismo caberia a tarefa de colocar-se como mediador no ato de trazer esse acontecimento exterior para a interioridade do texto. Tomase constantemente o texto jornalístico como transparente (ou seja, como um retrato fiel da realidade), estabelecendo uma distinção entre discurso e referente impensável nos estudos de discurso, em que a linguagem se coloca como opaca, isto é, como mediação (SOARES, 2010). Estão aí as concepções de verdade e de correspondência entre textos e relatos, ou seja, uma visão instrumental da linguagem. O trabalho de Zipser nos ajuda a pensar os acontecimentos noticiosos que transitam de um lugar ao outro a partir do entendimento de que estes textos não se limitam à tradução de textos-fontes, como os vindos de agências e publicados como traduzidos. A hipótese de Zipser é a de que a visão de tradução como transcodificação, fiel à letra, não é suficiente para que o texto traduzido se caracterize como jornalístico. Com isso, ela abre a discussão para um conceito ampliado de tradução no jornalismo. O texto traduzido, bem como o texto jornalístico, volta-se ao outro que busca interpelar, constituindo-o no interior de sua narrativa e na relação eu-outro. Dos gestos e esforços daqueles que escrevem a notícia resultariam as marcas culturais do texto.

10 Entre as pesquisas, uma analisa a tradução e a narratividade jornalística no caso do 11 de setembro em The New York Times e Folha Online, com interesse na tradução das manchetes (POLCHLOPECK, 2011); outras que procuram identificar as diferentes marcas culturais em revistas multilíngues como National Geographic; revistas de bordo bilíngues; ou na comparação entre revistas nacionais e internacionais. 
É por essas marcas culturais presentes nos textos jornalísticos, que somos levadas a aproximar o jornalista da figura do tradutor, que realiza uma espécie de "tradução cultural" nos moldes daquela apontada por M. Zipser e caracterizandose, assim, como uma das formas narrativas voltadas à fabulação do cotidiano. O chamado "fato jornalístico" seria, portanto, tecido no entremeio dessas narrativas, sempre provisório e contextual, traduzido nos interstícios da cultura.

Em Stuart Hall temos que leitores ou telespectadores assumem posições a partir das quais a decodificação se constrói: posição hegemônica-dominante, quando se apropriam do sentido conotado; código negociado, quando conferem lugar privilegiado às definições dominantes dos acontecimentos, mas aplicadas às suas próprias regras e condições locais; e ainda quando decodificam as notícias de maneira contrária, dentro de algum referencial alternativo (HALL, 2005, p.377380). Em vários de seus trabalhos, Hall procurou compreender as relações das mídias com cultura, linguagem e ideologia. Ao tratar do conceito de "tradução cultural", S. Hall (1996) apresenta sua teoria da articulação. Para ele essa palavra reveste-se de dois significados: articular significa em inglês, bem como em português, proferir e expressar uma ideia ou raciocínio, num sentido de construção na linguagem, de discurso, de comunicar-se bem. Também significa que duas partes distintas estão conectadas, mas não necessariamente precisariam estar ligadas uma à outra. As duas partes conectadas por meio de um elo específico podem ser quebradas, separadas, divididas. Uma articulação é, assim, a forma de conexão que pode constituir uma unidade de dois elementos diferentes sob certas condições. Uma dessas condições ou circunstâncias sugeridas por Hall é a questão do discurso. A chamada "unidade" do discurso é de fato a articulação de distintos elementos que podem ser rearticulados de formas variadas.

O conceito de "tradução cultural", para o autor, reveste-se desse aspecto ao mesmo tempo coeso e fluido presente na noção de articulação. Traduzir (fatos, textos) seria, portanto, rearticular (separar, reunir) as diversas partes de uma cultura. É justamente esse processo que o jornalismo, apoiado na retórica de objetividade e imparcialidade, pretende camuflar e elidir. Ao fazê-lo, perde de vista sua potência como acontecimento 
discursivo capaz de articular, de outros modos, elementos antes dispersos, traduzindo-os e recriando-os, dotando-os de novos sentidos sociais (SOARES; SILVA, 2012).

Em se tratando da investigação dessa abordagem em materiais empíricos específicos, interessa-nos tomar a escrita do texto jornalístico como sendo uma tradução prospectiva do fato noticioso por excelência, uma vez que o acontecimento noticioso dá origem ao texto jornalístico, que, resultante de diversas ações, concretiza-se no momento de sua recepção pelo leitor (ZIPSER, 2002, p.40). Por isso, a notícia, apresentada ao público pela imprensa em diferentes culturas, deve ser considerada a tradução do fato noticioso, no sentido de uma representação cultural: "(...) afirmamos que as diferentes leituras que fazemos acerca de um mesmo fato representam diferentes 'traduções' do mesmo, pois os processos constitutivos da elaboração da notícia se aproximam daqueles utilizados para a tradução" (ZIPSER; POLCHLOPECK, 2009, p.13). No contexto das afinidades entre tradução e jornalismo, podemos dizer que a transcodificação isenta seria para a tradução o que a neutralidade representa para o jornalismo. "Entretanto, considerar a possibilidade de que existam textos neutros e imparciais significa desconsiderar a linguagem como manifestação cultural, resultando na sua desvinculação como produto de um meio social e como processo formador de sentido" (ZIPSER; POLCHLOPECK, 2007).

São as diferenças nas construções das matérias jornalísticas sobre um mesmo acontecimento social que nos animam a pensar a notícia como tradução, mesmo nos casos de acontecimentos tratados jornalisticamente dentro de uma mesma cultura, como o caso da doença do ex-presidente Lula.

\section{A doença de Lula como diferentes acontecimentos jornalísticos}

A doença do ex-presidente Lula foi divulgada como notícia imediata no sábado 30 de outubro de 2011. No fim de semana seguinte, as revistas de informação Época, Veja, IstoÉ e Carta Capital, as quatro principais semanais brasileiras, estamparam em suas capas matérias sobre esse acontecimento 
(datas de 07 e 09 de novembro): capa da IstoÉ - "A grande batalha de Lula", com título interno igual. Capa da Veja - "Os bastidores da luta de Lula contra o câncer", título interno "O grande adversário: o câncer". Capa da Carta Capital - "Lula, a doença e a estupidez", título interno "Doentes de ódio". Capa da Época - "O SUS e o preconceito", título interno "A maior batalha de Lula", vindo em seguida a matéria correlata "O SUS que funciona / O SUS que fracassa" (grifos das autoras).
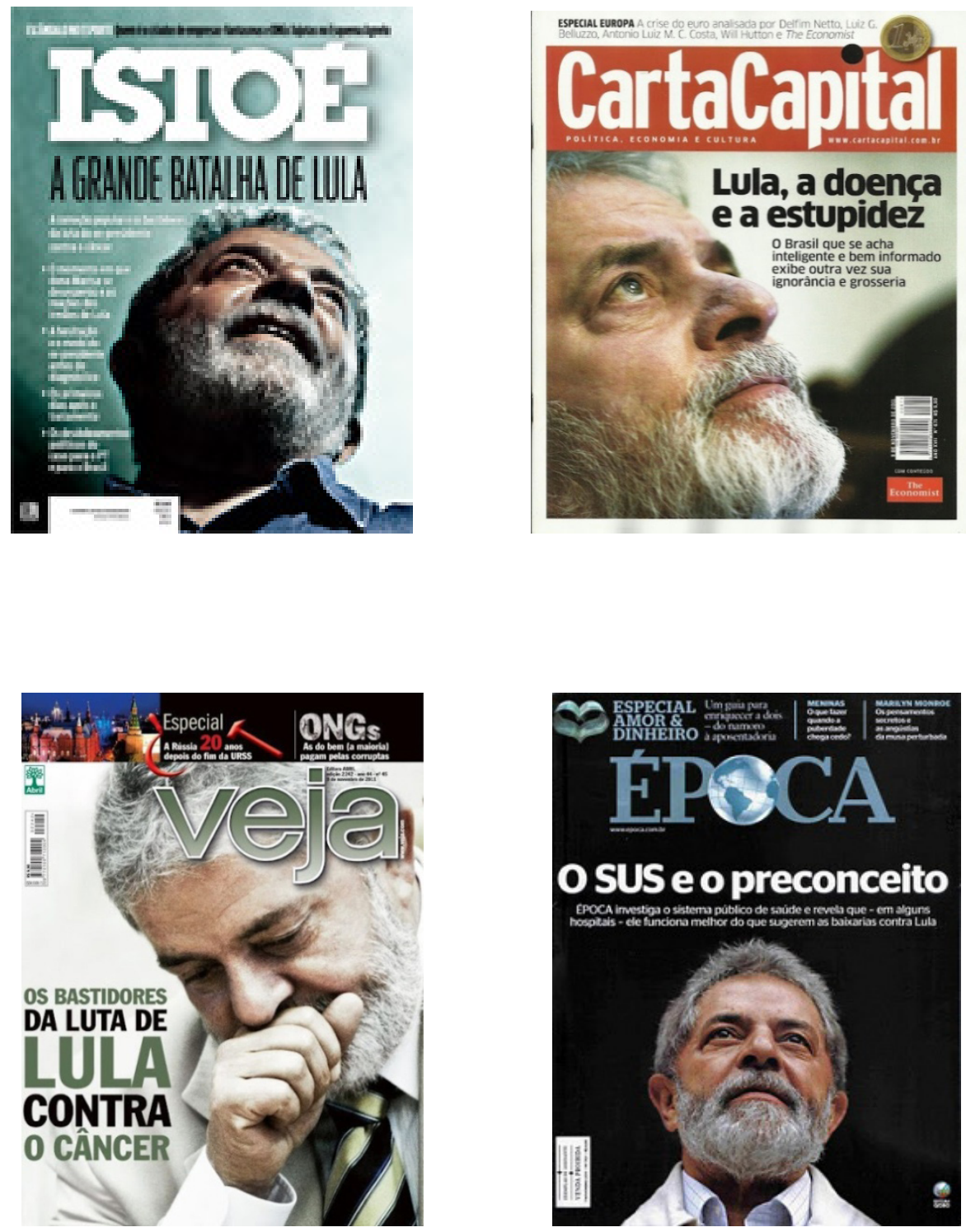
Já pelas manchetes, notamos diferenças significativas entre as revistas - notadamente pelos diferentes enfoques (ou angulações) eleitos para as chamadas (o presidente, a doença, a população e o sistema público de saúde no Brasil). Ao mesmo tempo, percebemos o contorno de um mesmo campo semântico e alguns traços recorrentes, entre eles a ausência de verbos nas manchetes de revistas (procedimento comum ao jornalismo de jornais e que indica, na maior parte das vezes, o sujeito da ação) e o uso de ênfase para se referir ao diagnóstico, tanto nas duas primeiras revistas (IstoÉ e Veja, em que a doença é um "adversário" a ser vencido em "luta" ou "batalha"), como nas seguinte (Carta Capital e Época), em que as reações à doença do expresidente (e, portanto, o entorno da doença) são destacadas, adjetivando as reações de parte da sociedade como "estupidez" e "preconceito". Deslizando da figura do presidente e do combate que deverá enfrentar para aqueles que por se colocarem em espectro político divergente do seu manifestaram-se de modo pouco condizente com a tragédia anunciada, as revistas reafirmam um percurso frequente, no jornalismo, quando são noticiadas doenças: é uma guerra que se inicia, na qual o protagonista deverá lutar e vencer, contanto com o apoio daqueles próximos a ele, já que, comumente, notícias como essas são acompanhadas de solidariedade.

Em todas as quatro, o rosto de Lula estampa a capa. Apenas em Veja, Lula está cabisbaixo, com a mão fechada frente à boca. Nas demais, as fotos trazem o ex-presidente com os olhos voltados ao infinito, em direção aos céus. Observando as marcas internas da composição pelo estudo comparativo entre essas quatro coberturas, vemos que as revistas deram espaço semelhante: Época e Carta Capital fizeram a matéria em 5 páginas, sendo que Carta Capital ainda fez correlata de 6 páginas sobre o SUS (Sistema Único de Saúde); Veja deu em 6 páginas e IstoÉ em 7 páginas. Todas elas abriram suas matérias em páginas duplas, com grande foto. Com exceção da Carta Capital, as demais deram infográficos para explicar a doença. Todas as matérias foram assinadas por repórteres da redação. 
São nas marcas da apuração que geralmente detectamos as estratégias de captura do acontecimento adotadas pelos veículos jornalísticos, muito especialmente na rede de fontes em que o repórter se lançou. Em todas elas há detalhes das decisões da equipe médica e informações sobre a doença e seu tratamento. As diferenças aparecem quando se observa a inserção das fontes. Em Veja não há depoimento de nenhum entrevistado. As poucas falas entre aspas são de Lula, já divulgadas na imprensa diária tão logo se soube da doença ou retiradas do vídeo gravado no hospital, quando ele agradece as mensagens de apoio recebidas dos amigos e da população. Em Época, aparecem depoimentos de médicos, da autora da biografia de Lula, do líder do PT, de cientista político. Na Carta Capital, utilizam-se reproduções de telefonema dado por Dilma ao cardiologista de Lula, reproduções de falas de Lula com os médicos, trechos do vídeo de agradecimento. Há referências a artigos de jornalistas em defesa ao respeito à doença do ex-presidente em contraposição às manifestações agressivas a Lula nas redes sociais. Há ainda falas de fontes que, participando de eventos públicos, fizeram referências à doença de Lula, como a presidente Dilma, o ex-presidente Fernando Henrique Cardoso, o governador Geraldo Alckmin e outros políticos da oposição. IstoÉ, além da reprodução de informações da equipe médica e de comentários de Lula já divulgados antes (como trechos do vídeo de agradecimento), traz ainda depoimentos de fontes entrevistadas diretamente, entre elas dois irmãos de Lula, filha, cientista político, publicitário.

Há dois aspectos de similitude entre as quatro reportagens. Primeiro, quanto às informações médicas ou referentes ao ânimo de Lula. Pelo fato de os médicos darem declarações em coletivas de imprensa, e não atenderem individualmente os jornalistas, e as visitas ao ex-presidente também falarem com a mídia coletivamente, as matérias das revistas repetem as mesmas informações sobre a doença, os detalhes do tratamento, a resposta do ex-presidente aos procedimentos e seu estado de humor e ânimo. Segundo, quanto à decisão de Lula de não esconder informação sobre seu câncer. Todas as quatro publicações destacaram, em forma de elogio, a transparência com que o ex-presidente optou por lidar com a própria doença, não escondendo nada da imprensa. 
Porém, fora tais semelhanças, a construção do acontecimento jornalístico se deu de modo bem diferente nas quatro revistas. Veja, que ficou somente com as informações médicas, construiu a matéria da doença de Lula elegendo a centralidade do câncer, cumprindo o prometido no título interno, "O grande adversário: o câncer". Praticamente todo o texto se limita a descrever o câncer, desde primeiros sintomas percebidos pelo ex-presidente, as causas prováveis, as decisões iniciais dos médicos, as possibilidades de tratamento, as reações ao tratamento, os efeitos colaterais, as chances de sucesso do paciente Lula. IstoÉ fez da doença de Lula uma matéria jornalística sobre a superação. As fontes familiares reforçaram a angulação. A tônica da matéria girou em torno de batalha, luta, dificuldades pessoais, manifestações de carinho e solidariedade, dos vínculos emocionais, na comoção popular pelo sofrimento do ex-presidente, na capacidade de superação de dificuldades do homem Lula. Mesmo quando abordou a situação de Lula doente no quadro político, o foco foi no não abatimento do vigor político do ex-presidente. Na Carta Capital, o investimento em fontes, depoimentos e declarações de políticos fez da doença de Lula o acontecimento jornalístico do embate entre as reações, contrapondo as manifestações nas redes sociais hostis a Lula e seu problema de saúde tratado num dos melhores hospitais do país, e percebidas como preconceito de classe contra o operário-presidente - às manifestações de apoio ao ex-presidente, até mesmo apoio de seus opositores. A matéria de Carta Capital deu pouca informação sobre a doença, suas causas e formas de tratamento. Época correu em duas direções. Optou por um texto menos pessoal ou intimista, focando-se de início, e de forma enxuta e rápida, na abordagem médica mais geral (o dia do primeiro exame, as causas, o tratamento, doenças antecedentes de Lula). O câncer só obteve destaque no boxe. Outro foco esteve no impacto político da doença do ex-presidente, na desaceleração esperada na atuação política de Lula. Na segunda matéria, a correlata sobre o SUS, a revista trouxe um exemplo de um caso de sucesso no tratamento de câncer igual ao do ex-presidente e um caso de fracasso, mostrando que o SUS não é único, é desigual quando se busca atendimento. 
Podemos concluir que Veja fez do fato doença de Lula o acontecimento jornalístico "a doença câncer"; IstoÉ construiu a notícia "homem Lula doente"; Carta Capital elaborou jornalisticamente a doença de Lula como "reação política" e "preconceito contra Lula"; e Época combinou no acontecimento jornalístico doença de Lula duas faces, "impacto político de Lula doente" e "preconceito contra o SUS". Com esta análise comparativa de materiais jornalísticos sobre a doença do ex-presidente Lula, pretendemos demonstrar a nossa hipótese de que as coberturas jornalísticas, entendidas como estratégias de apuração, composição e angulação, configuram um mesmo acontecimento social em diferentes acontecimentos jornalísticos. Ou seja, ao revelar aspectos do conteúdo e do discurso a respeito de um tema-problema tratado pela mídia noticiosa, este exercício quer pontuar que o fenômeno jornalístico mostra-se não somente como o lugar em que o acontecimento transforma-se em texto, mas também como a prática que transforma e recria acontecimentos, sendo o próprio jornalismo ator desse acontecimento. 


\section{Referências}

HALL, S. "Codificação/Decodificação". In: Da diáspora: identidades e mediações culturais. Belo Horizonte: Editora UFMG, 2005.

HALL, S. "On postmodernism and articulation". In: MORLEY, David \& CHEN, Kuan-Hsing. Stuart Hall: critical dialogues in cultural studies. Londres: Routledge, 1996, p.131-150.

SILVA, G. \& MAIA, F. D. Análise de cobertura jornalística: um protocolo metodológico. Revista Rumores. Edição 10, v.5, jul.-dez. 2011 a.

SILVA, G.; MAIA, F. D. O método Análise de Cobertura Jornalística na compreensão do crack como acontecimento noticioso. In: Jornalismo e acontecimento: percursos metodológicos / Bruno Souza Leal, Elton Antunes e Paulo Bernardo Vaz. Florianópolis: Insular, v.2, 2011b.

SOARES, R. de L. "Pequeno inventário de narrativas midiáticas: verdade e ficção em discursos audiovisuais". Significação - Revista de Cultura Audiovisual. Edição 34, jul.dez. de 2010, p.55-72.

SOARES, R.; SILVA, G. "O jornalismo como tradução: fabulação narrativa e imaginário social". XXI Encontro da COMPÓS (GT Cultura das Mídias). Anais. Universidade Federal de Juiz de Fora, Juiz de Fora, 2012.

ZIPSER, M. E. Do fato à reportagem: as diferenças de enfoque e a tradução como representação cultural. Tese de doutorado. São Paulo: FFLCH/USP, 2002.

ZIPSER, M. E. ; POLCHLOPEK, Silvana A. "Do fato à reportagem: o ambiente da tradução jornalística". Revista DitoEfeito. V. 1, 2009, p. 1-15.

. "Traduzindo notícias: as possibilidades da tradução em meio jornalístico". Revista Inventário. Vol.6, 2007, p.1-18. 